\title{
MELATONIN, ITS PRECURSORS, TOTAL PHENOLIC CONTENT AND ANTIOXIDANT ACTIVITY IN LEGUMES GERMINATED UNDER NORMAL AND SALINE CONDITIONS
}

\author{
SUPAP NONTASAN, PHEERAYA CHOTTANOM AND ANUCHITA MOONGNGARM*
}

Research Unit of Nutrition for Life, Department of Food Technology and Nutrition, Faculty of Technology, Mahasarakham University, Maha Sarakham, 44150, Thailand.

*Corresponding author: anuchitac@yahoo.co.th

Submitted final draft: 8 September $2020 \quad$ Accepted: 23 September $2020 \quad$ http://doi.org/10.46754/jssm.2021.02.007

\begin{abstract}
Legumes are a potent source of bioactive ingredients that may be enhanced in seed germination particularly under saline condition. The levels of melatonin, its precursors, total phenolic compounds (TPC) and antioxidant activity of selected legume seeds were evaluated. Soybeans (Glycine max), black beans (Phaseolus vulgaris), red kidney beans (Phaseolus vulgaris), chickpeas (Cicer arietinum) and lentils (Lens culinaris) were germinated with distilled water and sodium chloride solution $(67 \mathrm{mM}$ $\mathrm{NaCl}$ ), while ungerminated seeds served as control. Results indicated that legume seeds were a good dietary source of melatonin, serotonin and free tryptophan, as well as TPC. Germination of legume seeds, regardless of $\mathrm{NaCl}$ treatment, would stimulate melatonin, serotonin and tryptophan content, and also exhibited stronger antioxidant activity than ungerminated seeds. However, under saline condition, the levels of melatonin, serotonin, TPC and antioxidant activity were enhanced in soybeans, black beans and lentils, while chickpeas and red kidney beans exhibited higher levels of melatonin, TPC and antioxidant activity. These findings showed that the germination of legume seeds under saline stress to stimulate antioxidant defense mechanisms is a promising technique to improve the level of antioxidants like TPC, melatonin and its precursors, as well as antioxidant activity, in legume sprouts.
\end{abstract}

Keywords: Melatonin, Serotonin, Tryptophan, Total phenolic compounds, Legumes, Germination.

\section{Introduction}

Legumes are a good source of food for humans due to their nutritional potential, which is high in protein, essential amino acids, carbohydrates, dietary fiber, minerals and vitamins (LopezAmoros et al., 2006; Duenas et al., 2015). Legumes also contain considerable amounts of phytochemicals, such as phenolic compounds that possess many biological functions in human health (López-Amorós et al., 2006; Kim \& Cho, 2011; Duenas et al., 2015). Melatonin and its precursors are also some of the phytochemicals that play an important role in the human body. Melatonin (N-acetyl-5-methoxytryptamine) and serotonin (5-hydroxytryptamine) operate as indoleamine neurotransmitters in the nerve cells of mammals that are synthesized from tryptophan (Ramakrishna et al., 2011; Çaliskan et al., 2017). In plants, they are metabolites that function as regulators of growth and development, besides being potent antioxidants to prevent cell damage (Ramakrishna et al., 2011; Erland \& Saxena, 2017). The biosynthesis of melatonin and serotonin in plants starts from a common precursor (tryptophan) and involves a multi-step enzymatic process as shown in Figure 1.

In humans, melatonin and serotonin exhibit numerous biological functions, such as regulating sleep and the circadian rhythm, providing relief from jetlag and insomnia, and enhancing the immune system with antioxidant and anti-aging effects (Chen et al., 2011; Meng et al., 2017). Melatonin and serotonin have been ubiquitously detected in many plant species, especially seeds (Zhang et al., 2015; MartínCabrejus et al., 2017). Tryptophan is an essential amino acid generally found in legume seeds and 
serves as a precursor for the biosynthesis of serotonin and melatonin in plants and the human brain (Comai et al., 2007; Erland et al., 2016).

Nowadays, germinated legumes have gained considerable interest as a nutritious diet in many countries as they contain health-promoting phytochemicals. The effects of germination on the phytochemical profiles of legumes have been widely documented (López-Amorós et al., 2006; Guo et al., 2012). Germination conditions are considered to be an important factor affecting the production of secondary metabolites and bioactivity of sprouts. During seed germination, reactive oxygen species (ROS) will increasingly form in seed tissue due to dramatic increase in metabolic activity (El-Maarouf-Bouteau \& Bailly, 2008). ROS play a central role in plant signaling to activate antioxidant mechanisms during seed germination and growth. When seeds are subjected to environmental stress such as high salinity, the level of ROS will increase (Gomes \& Garcia, 2013) and cause the plants to suffer adverse effects of oxidative stress (Zhang et al., 2015; Ahanger et al., 2017). To reduce these harmful effects and modulate saline stress tolerance, plants have developed defense mechanisms (Waśkiewicz et al., 2013; Li et al., 2019).

Melatonin and its precursors play vital roles in plant development and stress defense. Zhang et al. (2015) reported that melatonin may make the plant robust to grow in harsh conditions, such as high salinity, extreme temperature and drought, by acting as a strong antioxidant to directly scavenge ROS and enhance endogenous antioxidants inside the plant cells. Levels of endogenous melatonin, serotonin and a variety of bioactive compounds also increased in plants growing under stressful conditions (Lim et al., 2012; Mukherjee et al., 2014; Zhang et al., 2015). Abundant evidence have suggested that salinity may affect the accumulation of healthbeneficial compounds, including total phenolics during seed germination and sprout growth in radish (Yuan et al., 2010), buckwheat (Lim et al., 2012), lentils (Swieca, 2015) and broccoli (Natella et al., 2016). However, information concerning melatonin and its precursors during seed germination and stress in legumes are rarely reported. Therefore, the effects of saline stress during germination on melatonin, serotonin, tryptophan and total phenolic compounds (TPC),
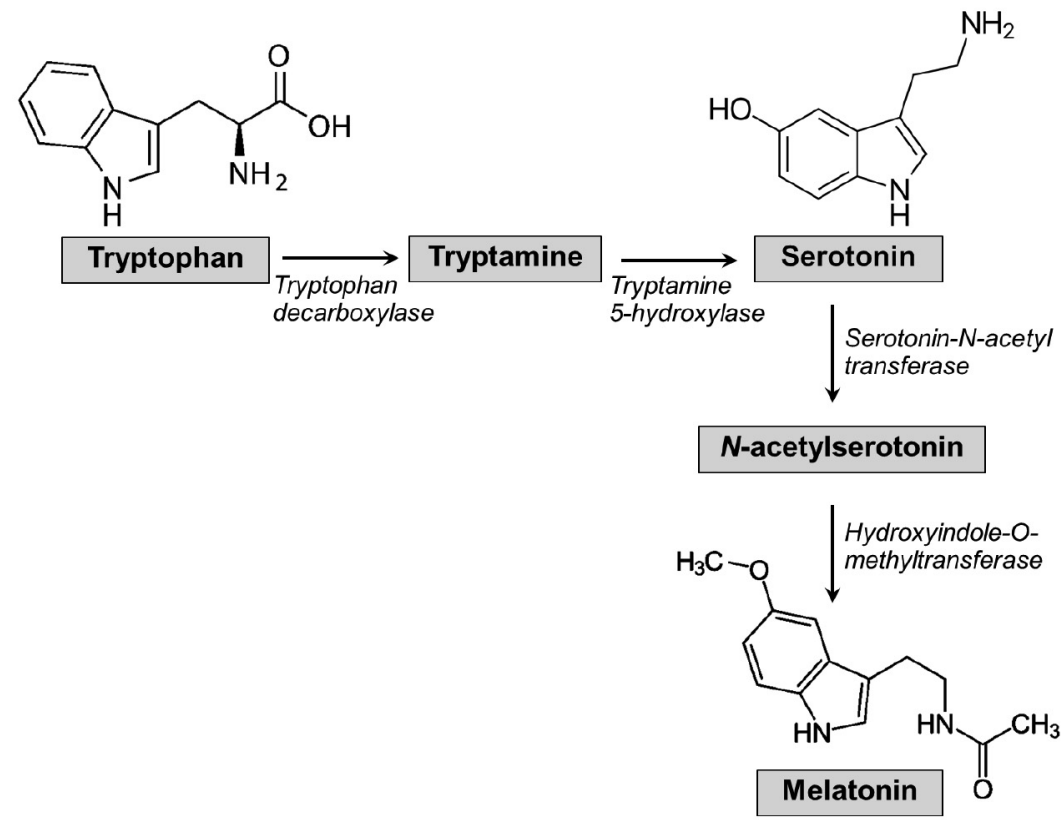

Figure 1: Molecular structures of melatonin, serotonin and tryptophan in the melatonin biosynthesis pathway in plants (adapted from Kaur et al., 2015) 
as well as the antioxidant activity in different types of germinated legumes, are evaluated in this study. The results will increase information on this promising technique to promote the production of healthy compounds in legume sprouts as a nutritional food source.

\section{Materials and Methods}

\section{Chemicals and Reagents}

Standards of melatonin, serotonin, tryptophan, gallic acid and Trolox $[( \pm)-6$-hydroxy-2,5,7,8tetramethylchromane-2-carboxylic acid] were purchased from Sigma-Aldrich (SigmaAldrich Chemical, St. Louis, MO, USA). DPPH (2,2-diphenyl-1-picrylhydrazyl), TPTZ (2,4,6-tripyridyl-s-triazine) and Folin-Ciocalteu phenol reagent were also obtained from SigmaAldrich (Sigma-Aldrich Chemical, St. Louis, MO, USA). Acetonitrile (HPLC grade) and methanol (HPLC grade) were obtained from LabScan (RCI LabScan, Dublin, Ireland). Ultrapure water was generated from a Milli-Q Purification System (Millipore, Bedford, MA, USA). All other reagents and solvents used were of analytical grade and purchased from recognized distributors.

\section{Equipment}

A Shimadzu 20 ADS Liquid Chromatograph coupled with a Shimadzu 8030 Mass Spectrometer (Shimadzu Corporation, Kyoto, Japan) and InertSustain ${ }^{\circledR}$ C18 column $(2.1 \times 150 \mathrm{~mm}$ i.d., $3 \mu \mathrm{m})$ (GL Science, Tokyo, Japan) were employed for analysis of melatonin, serotonin and tryptophan. The Libra S12 UVvis Spectrophotometer (Biochrom, Cambridge, UK) was used to determine TPC and antioxidant activity.

\section{Plant Materials and Germination}

Five legumes, namely soybeans (Glycine max), black beans (Phaseolus vulgaris), red kidney beans (Phaseolus vulgaris), chickpeas (Cicer arietinum) and lentils (Lens culinaris), were obtained from farms in northern Thailand. Preparation of germinated samples was carried out following the method of Lim et al. (2012) with modifications. Sorted sound seeds $(50 \mathrm{~g})$ were cleaned and soaked in distilled water for eight hours in a dark room at $25{ }^{\circ} \mathrm{C}$ with and without $67 \mathrm{mM}$ sodium chloride $(\mathrm{NaCl})$ for 72 h. The soaking water was then decanted, and the seeds were allowed to germinate on dishes lined with a layer of sterile sheet cloth in a dark seed germinator at $28{ }^{\circ} \mathrm{C}$ and $80 \%$ relative humidity. Three replicates were performed for each treatment. The seeds were sprayed with $100 \mathrm{ml}$ of sterile distilled water or $\mathrm{NaCl}$ solution daily. The $\mathrm{NaCl}$ solution was freshly prepared before use. Germinated legumes were collected, immediately freeze-dried, and ground into fine powder. The powder was passed through a 50mesh sieve and kept in a tightly closed and dark container at $-20{ }^{\circ} \mathrm{C}$ until analysis.

\section{Characterization of Germinated seeds}

Germination percentage and length of the germinated seeds were evaluated following the method of Mendoza-Sánchez et al. (2016). The number of germinated seeds was recorded after $72 \mathrm{~h}$ and divided by the total number of seeds to calculate the germination percentage (GP). Total sprout length was measured with a Vernier caliper by randomly sampling 40 germinated seeds from each tray.

\section{Determination of Melatonin, Free Tryptophan and Serotonin}

The extraction procedure of melatonin and its precursors followed the method described by Cao et al. (2006) with modifications. Each powder sample $(2 \mathrm{~g})$ was mixed with $80 \%$ methanol $(10 \mathrm{ml})$ before sonication for $30 \mathrm{~min}$. The resulting mixture was then shaken (150 $\mathrm{rpm})$ at $25^{\circ} \mathrm{C}$ for six hours in an incubator shaker, before centrifugation at $4{ }^{\circ} \mathrm{C}$ for $10 \mathrm{~min}$. The supernatant was separated and filtered through a Whatman No. 1 paper (Whatman, Maidstone, UK). Then, the filtered supernatant was purified according to the method described by Pothinuch \& Tongchitpakdee (2011) using a Sep-Pac C18 solid phase extraction (SPE) cartridge (Waters, Milford, MA, USA) before liquid 
chromatography-tandem mass spectrometry analysis (LC-MS/MS).

The LC-MS/MS analyses of melatonin and its precursors were carried out according to Cao et al. (2006) with modifications. The purified extract was passed through a $0.22 \mu \mathrm{m}$ syringe filter and analyzed using a Shimadzu 20 ADS Liquid Chromatograph coupled with a Shimadzu 8030 Mass Spectrometer operated in electrospray ionization (ESI) mode. Separation was performed with the InertSustain ${ }^{\circledR} \mathrm{C} 18$ column at $40{ }^{\circ} \mathrm{C}$ using isocratic elution of $0.45 \%$ formic acid and acetonitrile (50:50, v/v) with 2 $\mu \mathrm{l}$ of injection volume. The compounds were eluted at $0.2 \mathrm{ml} / \mathrm{min}$ for $10 \mathrm{~min}$ of total runtime.

Multiple reaction monitoring (MRM) in positive ion mode was performed to identify the compounds. Flows of nitrogen gas as a nebulizer and drying agent were set at 3 and 15 $\mathrm{L} / \mathrm{min}$, respectively, with interface voltage of $4.5 \mathrm{kv}$ and temperatures at 250 and $400{ }^{\circ} \mathrm{C}$ for desolvation line and heat block, respectively. For identification, a Q3 scan and targeted product ion scans were recorded using argon as the collision induced dissociation gas at a pressure of $230 \mathrm{kPa}$.

The transition of molecular ions from parent to daughter ion of melatonin, serotonin and free tryptophan was determined at $233.0 \rightarrow 174.0$ (collision energy; $\mathrm{CE}$ of $-15 \mathrm{ev}$ ), $177 \rightarrow 160$ (CE of $-12 \mathrm{ev}$ ) and $205 \rightarrow 188$ (CE of $-11 \mathrm{ev}$ ), respectively, with dwell time of $100 \mathrm{~ms}$. The retention times were $3.03 \mathrm{~min}$ for melatonin, $1.79 \mathrm{~min}$ for serotonin and $1.85 \mathrm{~min}$ for free tryptophan. Concentrations of melatonin, serotonin and tryptophan in the extract were calculated using a linear calibration curve of peak area versus concentration of standard. The content of melatonin and serotonin were reported in $\mathrm{ng} / \mathrm{g}$ of dry sample, while free tryptophan content was presented in $\mu \mathrm{g} / \mathrm{g}$ of dry sample.

\section{Determination of Total Phenolic Compounds}

Methanolic extracts of the samples were prepared according to the method by Pajak et al.
(2014) with minor modifications. The powder samples of raw and germinated legumes $(1 \mathrm{~g})$ were mixed with $10 \mathrm{ml}$ of $80 \%$ methanol. The mixtures were sonicated for $30 \mathrm{~min}$, placed in an incubator shaker $\left(150 \mathrm{rpm}\right.$ at $25^{\circ} \mathrm{C}$ for six hours) and centrifuged (4,500 rpm for $10 \mathrm{~min}$ ) before filtering the supernatant through a Whatman No.4 paper. TPC in the extracts were determined according to the Folin-Ciocalteu method of Singleton et al. (1999). In brief, $0.2 \mathrm{ml}$ of the filtered supernatant was added to $0.8 \mathrm{ml}$ FolinCiocalteu reagent diluted with water (1:10) and left at room temperature for one minute. Then, 2 $\mathrm{ml}$ of $7 \%$ sodium carbonate solution was added into the reaction mixture, followed by $4 \mathrm{ml}$ of distilled water to adjust the final volume to 7 $\mathrm{ml}$. The resulting mixture was vortexed and left in the dark for two hours at room temperature. Absorbance of the resulting reaction mixture was then read at $760 \mathrm{~nm}$ using the Libra S12 UV-vis Spectrophotometer. Concentration of TPC was calculated and expressed as mg of gallic acid equivalent per g (mg GAE/g) of dry sample.

\section{Determination of DPPH Radical Scavenging Activity}

Evaluation of DPPH radical scavenging activity of the legume seeds and sprouts was carried out according to the procedure of Brand-Williams et al. (1995). The reaction mixture was prepared by mixing $50 \mu 1$ of the extract (previously obtained for TPC determination) with $1.95 \mathrm{ml}$ of DPPH solution $\left(6 \times 10^{5} \mathrm{M}\right)$ and incubated in the dark at room temperature for $30 \mathrm{~min}$. Then, absorbance of the resulting mixture was read at $517 \mathrm{~nm}$, with results expressed as mg Trolox equivalent per g (mg TE/g) of dry sample.

\section{Determination of Ferric Reducing Antioxidant Power (FRAP)}

Determination of ferric reducing antioxidant power (FRAP) was performed following the method reported by Benzie and Strain (1996) with modification. FRAP reagent was prepared fresh by mixing $0.3 \mathrm{M}$ acetate buffer ( $\mathrm{pH}$ 3.6) with $10 \mathrm{mM}$ tripyridyl-s-triazine (TPTZ) 
solution (TPTZ in $40 \mathrm{mM}$ of $\mathrm{HCl}$ ) and $20 \mathrm{mM}$ $\mathrm{FeCl}_{3} \cdot 6 \mathrm{H}_{2} \mathrm{O}$ in a volume ratio of $10: 1: 1$. The reagent was then warmed in a water bath at $37^{\circ} \mathrm{C}$ for $30 \mathrm{~min}$ before use. For the assay, 0.3 $\mathrm{ml}$ of the extract previously obtained for TPC assay was mixed with $1.7 \mathrm{ml}$ of the working FRAP reagent and incubated in the dark for 60 min. Absorbance of the reaction mixture was monitored at $593 \mathrm{~nm}$, and results were expressed in $\mathrm{mg}$ Trolox equivalent per $\mathrm{g}(\mathrm{mg} \mathrm{TE} / \mathrm{g})$ of dry sample.

\section{Statistical Analysis}

Each treatment was performed in triplicates, and results were expressed as mean values \pm standard deviation. IBM SPSS software version 21 (IBM Corp, Armonk, NY, USA) was employed for the statistical analysis. Data were analyzed using independent sample t-test and one-way analysis of variance (one-way ANOVA) in a completely randomized design, followed by Duncan's multiple range test. Significant differences in mean values were considered at $\mathrm{p}<0.05$.

\section{Results and Discussion}

\section{Characteristics of Germinated Seeds}

Effects of $\mathrm{NaCl}$ on germination percentage and total sprout length of the selected legumes are presented in Table 1. The results showed no significant differences among germination percentages of legumes except for chickpeas. At $72 \mathrm{~h}$, soybeans and lentils under normal and saline conditions exhibited the highest germination percentage (over $90 \%$ ), while red kidney beans showed the lowest germination percentage (47.72-49.01\%).

Germination characteristics of legumes under normal condition at $72 \mathrm{~h}$ were consistent with Xue et al. (2016). Germination percentages of legume seeds varied among species at specific germination times. Xu et al. (2011) illustrated that under a salt treatment of $100 \mathrm{mM}$, only germination time of soybean seeds was delayed, while the final germination percentage of seeds was not severely affected. However, in this study, the shoot length of germinated legumes was significantly affected by saline treatment.

Application of $67 \mathrm{mM} \mathrm{NaCl}$ solution resulted in significant reduction of radicle length in germinated soybeans, black beans, red kidney beans and chickpeas compared with germination under normal condition, while slight decrease in length with no statistical difference was observed in lentils. These diversities could be attributed to the different tolerance to salt between the legumes. Reduction of total sprout length was due to the osmotic effect of salt during seed germination, resulting in lower amount of water absorbed and delay in germination and suppression of sprout growth (Chowdhury et al., 2018; Kaymakanova, 2009).

Table 1: Effect of seed germination under normal and saline $(67 \mathrm{mM} \mathrm{NaCl})$ conditions on germination percentage and total sprout length of selected legumes

\begin{tabular}{|c|c|c|c|c|}
\hline \multirow{2}{*}{ Legume } & \multicolumn{2}{|c|}{ Germination percentage (\%) } & \multicolumn{2}{|c|}{ Total length $(\mathrm{cm})$} \\
\hline & Normal & $\mathrm{NaCl}$ & Normal & $\mathrm{NaCl}$ \\
\hline Soybeans & $92.28 \pm 2.51^{\mathrm{A}, \mathrm{a}}$ & $90.79 \pm 2.04^{\mathrm{A}, \mathrm{a}}$ & $9.13 \pm 0.12^{\mathrm{A}, \mathrm{a}}$ & $7.60 \pm 0.46^{\mathrm{A}, \mathrm{b}}$ \\
\hline Black beans & $60.70 \pm 4.94^{\mathrm{B}, \mathrm{a}}$ & $58.07 \pm 4.72^{\mathrm{C}, \mathrm{a}}$ & $5.06 \pm 0.17^{\mathrm{B}, \mathrm{a}}$ & $3.39 \pm 0.10^{\mathrm{C}, \mathrm{b}}$ \\
\hline Red kidney beans & $49.01 \pm 0.66^{\mathrm{C}, \mathrm{a}}$ & $47.72 \pm 0.49^{\mathrm{D}, \mathrm{a}}$ & $1.16 \pm 0.04^{\mathrm{D}, \mathrm{a}}$ & $0.91 \pm 0.07^{\mathrm{D}, \mathrm{b}}$ \\
\hline Chickpeas & $87.45 \pm 2.67^{\mathrm{A}, \mathrm{a}}$ & $81.18 \pm 2.07^{\mathrm{B}, \mathrm{b}}$ & $1.67 \pm 0.09^{\mathrm{C}, \mathrm{a}}$ & $0.92 \pm 0.05^{\mathrm{D}, \mathrm{b}}$ \\
\hline Lentils & $92.52 \pm 4.42^{\mathrm{A}, \mathrm{a}}$ & $91.61 \pm 5.15^{\mathrm{A}, \mathrm{a}}$ & $5.12 \pm 0.25^{\mathrm{B}, \mathrm{a}}$ & $4.55 \pm 0.30^{\mathrm{Ba}}$ \\
\hline
\end{tabular}

Values within a column designated by different letters (A, B, C..) are significantly different $(\mathrm{p}<0.05)$. Values within a row designated by different letters $(a$ and $b)$ are significantly different $(p<0.05)$ as analyzed by independent sample t-test. Values are expressed as mean \pm standard deviation. 


\section{Effect of Germination on Melatonin Content}

Concentration of melatonin in germinated legumes when comparing germination conditions with ungerminated seeds is shown in Table 2. Melatonin concentration in ungerminated seeds varied depending on the types of legumes. Our results showed that highest concentration of melatonin in ungerminated seeds was found in black beans, followed by chickpeas, red kidney beans, soybeans and lentils. These results agreed with Manchester et al. (2000), who found that seeds of edible plants contained considerable amounts of melatonin (2-189 ng/g). Saleh et al. (2019) also reported the contents of melatonin in raw lentils (4.79 $\mathrm{ng} / \mathrm{g})$, chickpeas (24.42 $\mathrm{ng} / \mathrm{g})$ and common beans $(5.85 \mathrm{ng} / \mathrm{g})$, while Aguilera et al. (2015) found lower amounts in lentils $(0.5 \mathrm{ng} / \mathrm{g})$ and kidney beans $(1.0 \mathrm{ng} / \mathrm{g})$. Sangsopha et al. (2020) indicated that among the legumes they studied, soybeans exhibited the highest concentration of melatonin (56.49 $\mathrm{ng} / \mathrm{g})$, followed by red beans $(54.79 \mathrm{ng} / \mathrm{g})$. These variations could probably be due to differences in legume varieties and procedures used for extraction and quantification (Kołodziejczyk \& Posmyk, 2016; Martín-Cabrejas et al., 2017; Meng et al., 2017). In this study, legume seeds were considered as a natural source of melatonin that could exert beneficial effects on human health.

To assess changes in melatonin concentration, the selected legumes were germinated under normal condition (distilled water) and saline stress. Results indicated that germination under normal and saline conditions led to significant increase in melatonin concentration of all selected legumes compared with ungerminated seeds. Under normal condition, percentage increases of melatonin were in the following order: soybeans (160.96\%), chickpeas (133.47\%), lentils $(86.90 \%)$, red kidney beans $(67.14 \%)$, and black beans $(49.97 \%)$. These findings concurred with Saleh et al. (2019), who found that traditional germination of lentils, chickpeas and common beans led to a considerable elevation of melatonin in sprouts for three days, and the amounts increased with germination time.
Similar results for accumulation of melatonin during edible seed germination were reported by Aguilera et al. (2014), and Kim and Cho (2011). Our study demonstrated that the accumulation of melatonin was enhanced when legume seeds were subjected to $\mathrm{NaCl}$ treatment during germination. Exposure to $\mathrm{NaCl}$ at $67 \mathrm{mM}$ resulted in elevations of melatonin at $213.29 \%$ for soybeans, $181.15 \%$ for lentils, $145.91 \%$ for chickpeas, $82.23 \%$ for black beans and $73.07 \%$ for red kidney beans. Among the germinated legumes tested, chickpeas germinated under saline stress and normal condition exhibited the highest levels of melatonin (29.46 and 27.97 $\mathrm{ng} / \mathrm{g}$, respectively), followed by soybeans and black beans germinated with $\mathrm{NaCl}$ treatment.

Enhancement of melatonin during seed germination and sprout development under $\mathrm{NaCl}$ stress was also reported in sunflower sprouts germinated in two to four days with $120 \mathrm{mM} \mathrm{NaCl}$ treatment (Mukherjee et al., 2014), and in roots of nine-day old lupin sprouts (Arnao \& Hernández-Ruiz, 2013). Melatonin biosynthesis was induced probably due to its potential role as an antioxidant to protect embryos against oxidative damage caused by ROS formation during seed germination under stressful situations (Zhang et al., 2014; Arnao \& Hernández-Ruiz, 2014). Melatonin also played a significant role as an auxin-like hormone and a plant-growth regulator to activate seed germination and development, particularly under environmental stress (Arnao \& HernándezRuiz, 2014; Mukherjee et al., 2016). Previous study indicated that saline stress induced enzymatic regulation of melatonin biosynthesis through enhancement of hydroxyindole-Omethyltransferase activity, a rate-limiting enzyme of melatonin biosynthesis from $\mathrm{N}$-acetylserotonin (Mukherjee et al., 2014). Our results indicated that melatonin accumulation in the sprouts germinated under salinity was more enhanced than that in normal condition in response to excess ROS generated in tissues as seen in the reduction of sprout length. 


\section{Effect of Germination on Serotonin Content}

Serotonin is an indoleamine precursor to melatonin that had a vital role in plant growth and development (Paredes et al., 2009; Erland et al., 2016; Kaur et al., 2015). Among raw legume seeds evaluated in this study, high levels of serotonin were observed in soybeans and chickpeas. Only a few studies had reported the content of serotonin in legume seeds (Table 2). Our results concurred with Feldman and Lee (1985), who indicated that that the level was lower than $100 \mathrm{ng} / \mathrm{g}$, including in peas, soybeans, lima beans and peanuts.

In this study, serotonin levels of germinated legumes tested in both germination conditions were higher than ungerminated seeds $(p<0.05)$ (Table 2). Under normal condition, the relative increase of serotonin in legumes germinated for three days compared to ungerminateed seeds were as follows: $62.80 \mathrm{ng} / \mathrm{g}$ for soybeans (10.43\% higher), $61.41 \mathrm{ng} / \mathrm{g}$ for black beans (102.34\%), $45.86 \mathrm{ng} / \mathrm{g}$ for red kidney beans $(52.06 \%), 56.87 \mathrm{ng} / \mathrm{g}$ for lentils $(30.77 \%)$, and $71.35 \%$ for chickpeas $(33.81 \%)$. Furthermore, our findings indicated that accumulation of serotonin in soybeans, black beans, red kidney beans and lentils was further enhanced under saline condition at $72 \mathrm{~h}$ of germination. The highest increase was observed in black beans at $135.62 \%$, followed by red kidney beans (52.75\%), lentils (47.05\%), chickpeas $(27.01 \%)$, and soybeans $(25.71 \%)$. Similar observation was reported in sunflower sprouts by Mukherjee et al. (2014). They determined that under normal condition (absence of $\mathrm{NaCl}$ ), serotonin content (in roots and cotyledons) increased from $48 \mathrm{~h}$ to $96 \mathrm{~h}$, and reduced during the later stages of germination. They also found that salt treatment increased serotonin level within $48 \mathrm{~h}$ by up to $64.4 \%$ in roots and $60 \%$ in cotyledons of sunflower sprouts compared to the normal condition.

Alteration of serotonin content in legume seeds during germination and salt stress occurred because it was a precursor for melatonin biosynthesis and played similar roles with the latter (Ramakrishna et al., 2011; Kaur et al.,
2015; Erland et al., 2016; 2019; Mukherjee, 2018). In addition, previous report found that serotonin could enhance the resistance of plants to saline stress by modulating the flow of ions into the chloroplast (Pickles \& Sutcliffe, 1955). Higher accumulation of serotonin in sprouts under saline condition could be part of a protective mechanism to alleviate large amounts of ROS generated by saline stress, depending on the type and age of plants (Erland et al., 2016; Dharmawardhana et al., 2013).

\section{Effect of Germination on Free Tryptophan Content}

The selected legume seeds contained different amounts of free tryptophan $(\mathrm{p}<0.05)$ as presented in Table 2. Among the raw legumes, chickpeas exhibited the highest level of free tryptophan, followed by black beans, soybeans, red kidney beans and lentils. Contents of free tryptophan found here were much lower than data reported by Comai et al. (2007). They found that the concentration of free tryptophan in legumes ranged from 200 to $580 \mu \mathrm{g} / \mathrm{g}$, with the highest detected in chickpeas, followed by beans and soybeans. Our free tryptophan content was also slightly higher than values reported by Sangsopha et al. (2020). They indicated that contents of free tryptophan in legumes ranged from 0.14 to $2.62 \mu \mathrm{g} / \mathrm{g}$. These different values were likely due to the diverse methods used in extraction and analysis.

Free tryptophan content increased significantly when the seeds were germinated in normal and saline conditions. Under normal condition, free tryptophan content was significantly enhanced by $87.10 \%$ in soybeans, $44.42 \%$ in black beans, $21.55 \%$ in red kidney beans, $32.53 \%$ in chickpeas and $70.24 \%$ in lentils (Table 2). These results were in agreement with earlier studies showing significant increases of free tryptophan and total free amino acids in Cedrela fissilis seed germination within two to five days (Aragão et al., 2015). Accumulation of free amino acids, including free tryptophan, was a result of degradation of seed storage proteins for biosynthesis and energy generation 
during germination and sprout development (Tan-Wilson \& Wilson, 2012; Aragão et al., 2015). Increased levels of free tryptophan during germination were also associated with its involvement in the biosynthesis of melatonin and serotonin (Kaur et al., 2015).

The results also revealed that germination of legumes under saline stress had led to a noticeable decline in concentration of free tryptophan in soybeans, black beans and lentils $(p<0.05)$, while it slightly decreased in red kidney beans and chickpeas. This might probably be attributed to its role as a precursor for melatonin and serotonin biosynthesis during seed germination and, while under stress (Kaur et al., 2015). Mukherjee et al. (2014), the tryptophan was being used to synthesize serotonin and melatonin. However, when all sprouts germinated under saline condition were compared to ungerminated seeds, the levels of tryptophan were also significantly higher.

\section{Effect of Germination on Total Phenolic Content}

Phenolic compounds were secondary metabolites with potential biological activity. Contents of TPC in the studied legumes are shown in Table 2. Among raw legumes studied, soybeans presented the highest content of TPC, followed by black beans, red kidney beans, lentils and chickpeas. These values were similar and within the range of TPC reported by Mastura et al. (2017) in soybeans (1.56-2.09 mg GAE/g), black beans (2.38-4.53 mg GAE/g), red kidney beans (2.43-3.05 mg GAE/g), and chickpeas (1.44-2.12 mg GAE/g), and in lentils (1.54-2.55 mg GAE/g) by Xu \& Chang (2010).

Contents of TPC in different types of legumes were affected by germination conditions $(\mathrm{p}<0.05)$ (Table 2$)$. Under normal condition, germination of soybeans, chickpeas, and lentils resulted in an increase of TPC in sprouts $(\mathrm{p}<0.05)$, whereas a noticeable decrease was found in black beans and red kidney beans. Relative decrease was found at $17.42 \%$ for black beans and $4.05 \%$ for red kidney beans with respect to ungerminated seeds.
Decrease of TPC in black beans and red kidney beans after $72 \mathrm{~h}$ of germination occurred because of the loss of water-soluble phenolic compounds during soaking (GuajardoFlores et al., 2013; Singh et al., 2017). Similar results were also reported by Xue et al. (2016). However, in our study, TPC in germinated soybeans, chickpeas and lentils under normal condition significantly improved with 15.63, 34.64 and $18.84 \%$ relative increase, respectively. This elevation of TPC was consistent with observations by Saleh et al. (2019), who noted the increase in chickpeas and lentils during germination. Similar results were also observed by Cevallos-Casals and Cisneros-Zevallos (2010), who reported increases of TPC in 13 edible seeds, including soybeans and lentils, after germination compared to ungerminated seeds.

Our results also showed that application of $\mathrm{NaCl}$ stress could significantly induce accumulation of TPC in germinated legumes $(\mathrm{p}<0.05)$. However, relative decrease was found in germinated black beans under saline stress at $6.77 \%$ and lower in ungerminated seeds, but no significant difference was observed between the improved levels of TPC in ungerminated seeds. Earlier studies also reported the elevation of TPC in edible sprouts affected by various saline stress (Yuan et al., 2010; Lim et al., 2012, Swieca, 2015). High saline stress might cause harmful effects, and the change of TPC accumulation in response to these stresses depended on plant species, genotype and stress severity (dose and time) (Waśkiewicz et al., 2013). Previous studies reported that excessive ROS production under stressful conditions could activate plants to protect themselves by inducing the synthesis of various antioxidants, including phenolic compounds (Waśkiewicz et al, 2013; Lim et al., 2012). The accumulation of phenolic compounds was stimulated through the phenylpropanoid pathway, by which several endogenous hormones and enzymes like phenylalanine ammonia lyase (PAL) were activated (Liu et al., 2006; Rivero et al., 2011; Lim et al., 2012). 
Table 2: Effect of seed germination on content of melatonin, serotonin, free tryptophan and total phenolic compounds of germinated legumes under normal and saline $(67 \mathrm{mM} \mathrm{NaCl})$ conditions compared with ungerminated seeds

\begin{tabular}{lccc}
\hline Legume & \multicolumn{3}{c}{ Treatment } \\
\cline { 2 - 4 } & $\begin{array}{c}\text { Ungerminated } \\
\text { seeds }\end{array}$ & Normal germination & $\begin{array}{c}\text { Germination und } \\
\text { saline conditio }\end{array}$ \\
\hline Melatonin (ng/g DW) & $8.35 \pm 0.26^{\mathrm{D}, \mathrm{c}}$ & $21.79 \pm 1.47^{\mathrm{B}, \mathrm{b}}$ & $26.16 \pm 1.42^{\mathrm{B}, \mathrm{a}}$ \\
Soybeans & $14.29 \pm 0.82^{\mathrm{A}, \mathrm{c}}$ & $21.43 \pm 1.00^{\mathrm{B}, \mathrm{b}}$ & $26.04 \pm 1.49^{\mathrm{B}, \mathrm{a}}$ \\
Black beans & $9.95 \pm 0.98^{\mathrm{C}, \mathrm{b}}$ & $16.63 \pm 1.31^{\mathrm{C}, \mathrm{a}}$ & $17.22 \pm 1.03^{\mathrm{C}, \mathrm{a}}$ \\
Red kidney beans & $11.98 \pm 1.11^{\mathrm{B}, \mathrm{b}}$ & $27.97 \pm 0.92^{\mathrm{A}, \mathrm{a}}$ & $29.46 \pm 0.80^{\mathrm{A}, \mathrm{a}}$ \\
Chickpeas & $5.04 \pm 0.23^{\mathrm{E}, \mathrm{c}}$ & $9.42 \pm 0.25^{\mathrm{D}, \mathrm{b}}$ & $14.17 \pm 1.2^{\mathrm{D}, \mathrm{a}}$ \\
Lentils & & &
\end{tabular}

\section{Serotonin (ng/g DW)}

Soybeans

Black beans

Red kidney beans

Chickpeas

Lentils

Tryptophan ( $\mu \mathrm{g} / \mathrm{g}$ DW)
$56.87 \pm 1.32^{\mathrm{A}, \mathrm{c}}$

$30.35 \pm 2.98^{\mathrm{C}, \mathrm{c}}$

$30.16 \pm 1.68^{\mathrm{c}, \mathrm{b}}$

$53.32 \pm 1.72^{\mathrm{A}, \mathrm{b}}$

$43.49 \pm 1.75^{\mathrm{B}, \mathrm{b}}$
$62.80 \pm 3.73^{\mathrm{B}, \mathrm{b}}$

$61.41 \pm 5.83^{\mathrm{B}, \mathrm{b}}$

$45.86 \pm 1.95^{\mathrm{C}, \mathrm{a}}$

$71.35 \pm 2.23^{\mathrm{A}, \mathrm{a}}$

$56.87 \pm 1.90^{\mathrm{B}, \mathrm{a}}$
$71.49 \pm 1.22^{\mathrm{A}, \mathrm{a}}$

$71.51 \pm 4.10^{\mathrm{A}, \mathrm{a}}$

$46.07 \pm 2.96^{\mathrm{B}, \mathrm{a}}$

$67.72 \pm 5.32^{\mathrm{A}, \mathrm{a}}$

$63.95 \pm 5.69^{\mathrm{A}, \mathrm{a}}$

$\begin{array}{lccc}\text { Soybeans } & 3.41 \pm 0.05^{\mathrm{C}, \mathrm{c}} & 6.38 \pm 0.23^{\mathrm{C}, \mathrm{a}} & 5.69 \pm 0.38^{\mathrm{C}, \mathrm{b}} \\ \text { Black beans } & 5.02 \pm 0.13^{\mathrm{B}, \mathrm{c}} & 7.25 \pm 0.19^{\mathrm{B}, \mathrm{a}} & 6.42 \pm 0.54^{\mathrm{B}, \mathrm{b}} \\ \text { Red kidney beans } & 2.83 \pm 0.12^{\mathrm{D}, \mathrm{b}} & 3.44 \pm 0.20^{\mathrm{D}, \mathrm{a}} & 3.24 \pm 0.09^{\mathrm{D}, \mathrm{a}} \\ \text { Chickpeas } & 7.84 \pm 0.13^{\mathrm{A}, \mathrm{b}} & 10.39 \pm 0.15^{\mathrm{A}, \mathrm{a}} & 9.98 \pm 0.29^{\mathrm{A}, \mathrm{a}} \\ \text { Lentils } & 1.68 \pm 0.05^{\mathrm{E}, \mathrm{c}} & 2.86 \pm 0.15^{\mathrm{E}, \mathrm{a}} & 2.18 \pm 0.02^{\mathrm{E}, \mathrm{b}}\end{array}$

\section{TPC (mg GAE/g DW)}

Soybeans

Black beans

Red kidney beans

Chickpeas

Lentils
$3.39 \pm 0.24^{\mathrm{A}, \mathrm{c}}$

$3.10 \pm 0.04^{\mathrm{B}, \mathrm{a}}$

$2.22 \pm 0.19^{\mathrm{C}, \text { a }}$

$1.79 \pm 0.07^{\mathrm{D}, \mathrm{c}}$

$2.07 \pm 0.09^{\mathrm{C}, \mathrm{c}}$
$3.92 \pm 0.03^{\mathrm{A}, \mathrm{b}}$

$2.56 \pm 0.18^{\mathrm{B}, \mathrm{b}}$

$2.13 \pm 0.04^{\mathrm{C}, \mathrm{a}}$

$2.41 \pm 0.08^{\mathrm{B}, \mathrm{b}}$

$2.46 \pm 0.12^{\mathrm{B}, \mathrm{b}}$
$4.46 \pm 0.16^{\mathrm{A}, \mathrm{a}}$

$2.89 \pm 0.12^{\mathrm{B}, \mathrm{a}}$

$2.36 \pm 0.06^{\mathrm{D}, \mathrm{a}}$

$2.61 \pm 0.06^{\mathrm{C}, \mathrm{a}}$

$2.73 \pm 0.11^{\mathrm{BC}, \mathrm{a}}$

Values within a column designated by different letters (A, B, C..) are significantly different $(\mathrm{p}<0.05)$. Values within a row designated by different letters $(\mathrm{a}, \mathrm{b}, \mathrm{c} .$.$) are significantly different (\mathrm{p}<0.05)$. Values are expressed as mean \pm standard deviation $(\mathrm{n}=3)$. DW - dry weight, TPC- total phenolic compounds. 


\section{Effect of Germination on Antioxidant Capacity}

The antioxidant profile evaluated by DPPH radical scavenging and FRAP assay of ungerminated legume seeds and sprouts after $72 \mathrm{~h}$ of germination under saline and normal conditions is shown in Table 3. Germination promoted the antioxidant activity of soybeans, black beans, red kidney beans, lentils, and chickpeas $(p<0.05)$. These observations were in agreement with previous studies on enhancement of antioxidant profile in legumes by germination (Lin \& Lai, 2006; Cevallos-Casals \& CisnerosZevallos, 2010; Tarzi et al., 2012; Aguilera et al., 2014; Xue et al., 2016; Saleh et al., 2019).

Our data also showed that the increase in antioxidant activity of germinated legumes was more pronounced in legume seeds treated with $\mathrm{NaCl}$ during germination $(\mathrm{p}<0.05)$, resulting in higher percentage increase than normal condition. Increases in antioxidant activity of sprouts under saline stress evaluated by DPPH and FRAP assays, respectively, were $37.65 \%$ and $50.71 \%$ for soybeans, $17.43 \%$ and $10.67 \%$ for black beans, $17.48 \%$ and $14.18 \%$ for red kidney beans, $41.86 \%$ and $58.06 \%$ for chickpeas, and $36.09 \%$ and $40.00 \%$ for lentils. It is obvious that changes in antioxidant capacity levels of these sprouts in response to saline treatment were consistent with changes of melatonin and TPC in sprouts germinated under saline stress. This could be attributed to the strong antioxidant effects of melatonin and TPC accumulated during stressful conditions (Waśkiewicz et al, 2013; Li et al., 2019; Verde et al., 2019).

After germination for $72 \mathrm{~h}$, legumes sprouted in saline condition exhibited higher values of antioxidant activity as assessed by DPPH and FRAP. The profiles of DPPH and

Table 3: Effect of seed germination under normal and saline $(67 \mathrm{mM} \mathrm{NaCl})$ conditions on antioxidant activity analyzed by DPPH and FRAP assay compared with ungerminated seeds

\section{Treatment}

\section{Legume}

Ungerminated seeds Normal germination

Germination under saline condition

\section{DPPH (mg TE/g DW)}

$\begin{array}{llll}\text { Soybeans } & 0.85 \pm 0.05^{\mathrm{B}, \mathrm{c}} & 1.03 \pm 0.04^{\mathrm{B}, \mathrm{b}} & 1.17 \pm 0.02^{\mathrm{B}, \mathrm{a}} \\ \text { Black beans } & 1.09 \pm 0.01^{\mathrm{A}, \mathrm{b}} & 1.17 \pm 0.07^{\mathrm{A}, \mathrm{b}} & 1.28 \pm 0.05^{\mathrm{A}, \mathrm{a}} \\ \text { Red kidney beans } & 1.03 \pm 0.08^{\mathrm{A}, \mathrm{c}} & 1.20 \pm 0.04^{\mathrm{A}, \mathrm{a}} & 1.21 \pm 0.02^{\mathrm{A}, \mathrm{a}} \\ \text { Chickpeas } & 0.43 \pm 0.01^{\mathrm{C}, \mathrm{c}} & 0.53 \pm 0.05^{\mathrm{C}, \mathrm{b}} & 0.61 \pm 0.02^{\mathrm{C}, \mathrm{a}} \\ \text { Lentils } & 0.92 \pm 0.02^{\mathrm{B}, \mathrm{c}} & 1.15 \pm 0.01^{\mathrm{A}, \mathrm{b}} & 1.26 \pm 0.02^{\mathrm{A}, \mathrm{a}}\end{array}$

\section{FRAP (mg TE/g DW)}

$\begin{array}{llcl}\text { Soybeans } & 1.40 \pm 0.03^{\mathrm{B}, \mathrm{c}} & 1.95 \pm 0.01^{\mathrm{A}, \mathrm{b}} & 2.11 \pm 0.06^{\mathrm{A}, \mathrm{a}} \\ \text { Black beans } & 1.78 \pm 0.09^{\mathrm{A}, \mathrm{b}} & 1.85 \pm 0.07^{\mathrm{B}, \mathrm{ab}} & 1.97 \pm 0.04^{\mathrm{B}, \mathrm{a}} \\ \text { Red kidney beans } & 1.41 \pm 0.03^{\mathrm{B}, \mathrm{b}} & 1.56 \pm 0.01^{\mathrm{C}, \mathrm{a}} & 1.61 \pm 0.05^{\mathrm{D} \text {, a }} \\ \text { Chickpeas } & 0.62 \pm 0.03^{\mathrm{D}, \mathrm{c}} & 0.87 \pm 0.06^{\mathrm{D}, \mathrm{b}} & 0.98 \pm 0.05^{\mathrm{E}, \mathrm{a}} \\ \text { Lentils } & 1.30 \pm 0.01^{\mathrm{C}, \mathrm{c}} & 1.58 \pm 0.06^{\mathrm{C}, \mathrm{b}} & 1.82 \pm 0.03^{\mathrm{C}, \mathrm{a}}\end{array}$

Values within a row designated by different letters (A, B, C..) are significantly different $(\mathrm{p}<0.05)$. Values within a column designated by different letters $(a, b, c .$.$) are significantly different (p<0.05)$. Values are expressed as mean \pm standard deviation ( $\mathrm{n}=3)$. DW-dry weight. 
FRAP antioxidant activity were as follows: 1.17 and $2.21 \mathrm{mg}$ TE/g for soybeans, 1.28 and $1.97 \mathrm{mg} \mathrm{TE} / \mathrm{g}$ for black beans, 1.21 and 1.61 $\mathrm{mg} \mathrm{TE} / \mathrm{g}$ for red kidney beans, 1.26 and 1.82 $\mathrm{mg} \mathrm{TE} / \mathrm{g}$ for lentils, and 0.61 and $0.98 \mathrm{mg} \mathrm{TE} / \mathrm{g}$ for chickpeas. Similar elevation in antioxidant activity of edible sprouts was also observed in buckwheat sprouts treated with 10-200 mM $\mathrm{NaCl}$ (Lim et al., 2012), lentil sprouts with 300 $\mathrm{mM} \mathrm{NaCl}$ (Swieca, 2014), and radish sprouts with $100 \mathrm{mM} \mathrm{NaCl}$ (Yuan et al., 2010).

\section{Conclusion}

This study indicated that germination process stimulated the accumulation of antioxidants and their activity in legume sprouts. Germination of legume seeds in $67 \mathrm{mM} \mathrm{NaCl}$ for $72 \mathrm{~h}$ was considered a safe level that did not cause negative effects on germination percentage. These findings suggested that the application of appropriate $\mathrm{NaCl}$ stress during seed germination might be an alternative and promising strategy to boost the level of health-promoting compounds - melatonin, serotonin, tryptophan and antioxidants of legume sprouts - which could be a good source of bioactive nutrients in functional food product development.

\section{Acknowledgements}

This research was financially supported by the Thailand Research Fund (TRF) through the Royal Golden Jubilee Ph.D. Programme (Grant No. PHD/0068/2559) and Faculty of Technology, Mahasarakham University, Thailand (Grant year 2021).

\section{References}

Aguilera, Y., Liébana, R., Herrera, T., RebolloHernanz, M., Sanchez-Puelles, C., Benítez, V., \& Martín-Cabrejas, M. A. (2014). Effect of illumination on the content of melatonin, phenolic compounds, and antioxidant activity during germination of lentils (Lens culinaris L.) and kidney beans (Phaseolus vulgaris L.). Journal of Agricultural and Food Chemistry, 62(44), 10736-10743.
Aguilera, Y., Herrera, T., Liébana, R., RebolloHernanz, M., Sanchez-Puelles, C., \& Martín-Cabrejas, M. A. (2015). Impact of melatonin enrichment during germination of legumes on bioactive compounds and antioxidant activity. Journal of Agricultural and Food Chemistry, 63(36), 7967-7974.

Ahanger, M. A., Tomar, N. S., Tittal, M., Argal, S., \& Agarwal, R. M. (2017). Plant growth under water/salt stress: ROS production; antioxidants and significance of added potassium under such conditions. Physiology and Molecular Biology of Plants, 23(4), 731-744.

Aragão, V. P. M., Navarro, B. V., Passamani, L. Z., Macedo, A. F., Floh, E. I. S., Silveira, V., \& Santa-Catarina, C. (2015). Free amino acids, polyamines, soluble sugars and proteins during seed germination and early seedling growth of Cedrela fissilis Vellozo (Meliaceae), an endangered hardwood species from the Atlantic Forest in Brazil. Theoretical and Experimental Plant Physiology, 27(2), 157-169.

Arnao, M. B., \& Hernández-Ruiz, J. (2013). Growth conditions determine different melatonin levels in Lupinus albus L. Journal of Pineal Research, 55(2), 149-155.

Arnao, M. B., \& Hernández-Ruiz, J. (2014). Melatonin: plant growth regulator and/ or biostimulator during stress?. Trends in Plant Science, 19(12), 789-797.

Benzie, I. F., \& Strain, J. J. (1996). The ferric reducing ability of plasma (FRAP) as a measure of "antioxidant power": the FRAP assay. Analytical Biochemistry, 239(1), 7076.

Brand-Williams, W., Cuvelier, M. E., \& Berset, C. L. W. T. (1995). Use of a free radical method to evaluate antioxidant activity. LWT-Food Science and Technology, 28(1), 25-30.

Çaliskan, U. K., Aka, C., \& Bor, E. (2017). Melatonin in edible and non-edible plants. Turkish Journal of Pharmaceutical Sciences, 14(1), 75-83. 
Cao, J., Murch, S. J., O’Brien, R., \& Saxena, P. K. (2006). Rapid method for accurate analysis of melatonin, serotonin and auxin in plant samples using liquid chromatographytandem mass spectrometry. Journal of Chromatography A, 1134(1-2), 333-337.

Chen, C. Q., Fichna, J., Bashashati, M., Li, Y. Y., \& Storr, M. (2011). Distribution, function and physiological role of melatonin in the lower gut. World Journal of Gastroenterology: WJG, 17(34), 3888.

Cevallos-Casals, B. A., \& Cisneros-Zevallos, L. (2010). Impact of germination on phenolic content and antioxidant activity of 13 edible seed species. Food Chemistry, 119(4), 1485-1490.

Comai, S., Bertazzo, A., Bailoni, L., Zancato, M., Costa, C. V., \& Allegri, G. (2007). The content of proteic and nonproteic (free and protein-bound) tryptophan in quinoa and cereal flours. Food Chemistry, 100(4), 1350-1355.

Dharmawardhana, P., Ren, L., Amarasinghe, V., Monaco, M., Thomason, J., Ravenscroft, D., ... \& Jaiswal, P. (2013). A genome scale metabolic network for rice and accompanying analysis of tryptophan, auxin and serotonin biosynthesis regulation under biotic stress. Rice, 6(1), 1-15.

Duenas, M., Martínez-Villaluenga, C., Limon, R. I., Peñas, E., \& Frias, J. (2015). Effect of germination and elicitation on phenolic composition and bioactivity of kidney beans. Food Research International, 70, 55-63.

El-Maarouf-Bouteau, H., \& Bailly, C. (2008). Oxidative signaling in seed germination and dormancy. Plant Signaling \& Behavior, 3(3), 175-182.

Erland, L. A., Turi, C. E., \& Saxena, P. K. (2016). Serotonin: An ancient molecule and an important regulator of plant processes. Biotechnology Advances, 34(8), 1347-1361.
Erland, L. A. E., \& Saxena, P. K. (2017). Beyond a neurotransmitter: The role of serotonin in plants. Neurotransmitter, 4, e1538.

Erland, L. A., Turi, C. E., \& Saxena, P. K. (2019). Serotonin in Plants: Origin, Functions, and Implications. In Serotonin (pp. 23-46). Academic Press.

Feldman, J. M., \& Lee, E. M. (1985). Serotonin content of foods: effect on urinary excretion of 5-hydroxyindoleacetic acid. The American Journal of Clinical Nutrition, 42(4), 639-643.

Gomes, M., \& Garcia, Q. (2013). Reactive oxygen species and seed germination. Biologia, 68(3), 351-357.

Guajardo-Flores, D., Serna-Saldívar, S. O., \& Gutiérrez-Uribe, J. A. (2013). Evaluation of the antioxidant and antiproliferative activities of extracted saponins and flavonols from germinated black beans (Phaseolus vulgaris L.). Food Chemistry, 141(2), 1497-1503.

Guo, X., Li, T., Tang, K., \& Liu, R. H. (2012). Effect of germination on phytochemical profiles and antioxidant activity of mung bean sprouts (Vigna radiata). Journal of Agricultural and Food Chemistry, 60(44), 11050-11055.

Kaymakanova, M. (2009). Effect of salinity on germination and seed physiology in bean (Phaseolus vulgaris L.). Biotechnology \& Biotechnological Equipment, 23(sup1), 326-329.

Kaur, H., Mukherjee, S., Baluska, F., \& Bhatla, S. C. (2015). Regulatory roles of serotonin and melatonin in abiotic stress tolerance in plants. Plant Signaling \& Behavior, 10(11), e1049788.

Kim, S. J., \& Cho, M. H. (2011). Melatonin and polyphenol contents in some edible sprouts (alfalfa, chicory, rape, red kale and sunflower). Preventive Nutrition and Food Science, 16(2), 184-188. 
Kołodziejczyk, I., \& Posmyk, M. M. (2016). Melatonin-a new plant biostimulator. Journal of Elementology, 21(4), 1187-1198.

Li, J., Liu, J., Zhu, T., Zhao, C., Li, L., \& Chen, M. (2019). The role of melatonin in salt stress responses. International Journal of Molecular Sciences, 20(7), 1735.

Lim, J. H., Park, K. J., Kim, B. K., Jeong, J. W., \& Kim, H. J. (2012). Effect of salinity stress on phenolic compounds and carotenoids in buckwheat (Fagopyrum esculentum M.) sprout. Food Chemistry, 135(3), 10651070 .

Lin, P. Y., \& Lai, H. M. (2006). Bioactive compounds in legumes and their germinated products. Journal of Agricultural and Food Chemistry, 54(11), 3807-3814.

Liu, L., Zang, X., \& Yuan, Q. (2006). Mitigating effect of exogenous sucrose on root growth of buckwheat (Fagopyrum esculentum Moench) seedlings under salt stress. Plant Physiology Communications, 42(5), 847.

López-Amorós, M. L., Hernández, T., \& Estrella, I. (2006). Effect of germination on legume phenolic compounds and their antioxidant activity. Journal of Food Composition and Analysis, 19(4), 277-283.

Martín-Cabrejas, M. A., Aguilera, Y., Benitez, V., \& Reiter, R. J. (2017). Melatonin synthesis in fermented foods. In Fermented Foods in Health and Disease Prevention (pp. 105129). Academic Press.

Mastura, H. Y., Hasnah, H., \& Dang, T. N. (2017). Total phenolic content and antioxidant capacity of beans: organic vs inorganic. International Food Research Journal, 24(2), 510-517.

Meng, X., Li, Y., Li, S., Zhou, Y., Gan, R. Y., Xu, D. P., \& Li, H. B. (2017). Dietary sources and bioactivities of melatonin. Nutrients, 9(4), 367.

Mukherjee, S., David, A., Yadav, S., Baluška, F., \& Bhatla, S. C. (2014). Salt stress $\square$ induced seedling growth inhibition coincides with differential distribution of serotonin and melatonin in sunflower seedling roots and cotyledons. Physiologia Plantarum, 152(4), 714-728.

Mukherjee, S., Arora, D., \& Bhatla, S. C. (2016). Serotonin and Melatonin as Metabolic Signatures for the Modulation of Seed Development, Seedling Growth, and Stress Acclimatization. In Serotonin and Melatonin (pp. 95-106). CRC Press.

Mukherjee, S. (2018). Novel perspectives on the molecular crosstalk mechanisms of serotonin and melatonin in plants. Plant Physiology and Biochemistry, 132, 33-45.

Mendoza-Sánchez, M., Guevara-González, R. G., Castaño-Tostado, E., Mercado-Silva, E. M., Acosta-Gallegos, J. A., Rocha-Guzmán, N. E., \& Reynoso-Camacho, R. (2016). Effect of chemical stress on germination of cv Dalia bean (Phaseolus vularis L.) as an alternative to increase antioxidant and nutraceutical compounds in sprouts. Food Chemistry, 212, 128-137.

Natella, F., Maldini, M., Nardini, M., Azzini, E., Foddai, M. S., Giusti, A. M., ... \& Scaccini, C. (2016). Improvement of the nutraceutical quality of broccoli sprouts by elicitation. Food Chemistry, 201, 101-109.

Pajak, P., Socha, R., Gałkowska, D., Rożnowski, J., \& Fortuna, T. (2014). Phenolic profile and antioxidant activity in selected seeds and sprouts. Food Chemistry, 143, 300-306.

Paredes, S. D., Korkmaz, A., Manchester, L. C., Tan, D. X., \& Reiter, R. J. (2009). Phytomelatonin: a review. Journal of Experimental Botany, 60(1), 57-69.

Pickles, V. R., \& Sutcliffe, J. F. (1955). The effects of 5-hydroxytryptamine, indole3-acetic acid, and some other substances, on pigment effusion, sodium uptake, and potassium efflux, by slices of red beetroot in vitro. Biochimica et Biophysica Acta, 17, 244-251

Pothinuch, P., \& Tongchitpakdee, S. (2011). Melatonin contents in mulberry (Morus spp.) leaves: effects of sample preparation, 
cultivar, leaf age and tea processing. Food Chemistry, 128(2), 415-419.

Ramakrishna, A., Giridhar, P., \& Ravishankar, G. A. (2011). Phytoserotonin: a review. Plant Signaling \& Behavior, 6(6), 800-809.

Rivero, R. M., Ruiz, J. M., Garcıa, P. C., LopezLefebre, L. R., Sánchez, E., \& Romero, L. (2001). Resistance to cold and heat stress: accumulation of phenolic compounds in tomato and watermelon plants. Plant Science, 160(2), 315-321.

Saleh, H. M., Hassan, A. A., Mansour, E. H., Fahmy, H. A., \& El-Bedawey, A. E. F. A. (2019). Melatonin, phenolics content and antioxidant activity of germinated selected legumes and their fractions. Journal of the Saudi Society of Agricultural Sciences, 18(3), 294-301.

Singh, B., Singh, J. P., Kaur, A., \& Singh, N. (2017). Phenolic composition and antioxidant potential of grain legume seeds: Areview. Food Research International, 101, $1-16$.

Singleton, V. L., Orthofer, R., \& LamuelaRaventós, R. M. (1999). Analysis of total phenols and other oxidation substrates and antioxidants by means of Folin-Ciocalteu reagent. In Methods in Enzymology (Vol. 299, pp. 152-178). Academic press.

Swieca, M. (2015). Elicitation with abiotic stresses improves pro-health constituents, antioxidant potential and nutritional quality of lentil sprouts. Saudi Journal of Biological Sciences, 22(4), 409-416.

Tan $\square$ Wilson, A. L., \& Wilson, K. A. (2012). Mobilization of seed protein reserves. Physiologia Plantarum, 145(1), 140-153.

Tarzi, B. G., Gharachorloo, M., Baharinia, M., \& Mortazavi, S. A. (2012). The effect of germination on phenolic content and antioxidant activity of chickpea. Iranian Jjournal of Ppharmaceutical Rresearch: IJPR, 11(4), 1137.
Verde, A., Míguez, J. M., \& Gallardo, M. (2019). Melatonin and related bioactive compounds in commercialized date palm fruits (Phoenix dactylifera L.): correlation with some antioxidant parameters. European Food Research and Technology, 245(1), 51-59.

Waśkiewicz, A., Muzolf-Panek, M., \& Goliński, P. (2013). Phenolic content changes in plants under salt stress. In Ecophysiology and Responses of Plants under Salt Stress (pp. 283-314). Springer, New York, NY.

Xu, B., \& Chang, S. K. (2010). Phenolic substance characterization and chemical and cell-based antioxidant activities of 11 lentils grown in the Northern United States. Journal of Agricultural and Food Chemistry, 58(3), 1509-1517.

Xu, X. Y., Fan, R., Zheng, R., Li, C. M., \& Yu, D. Y. (2011). Proteomic analysis of seed germination under salt stress in soybeans. Journal of Zhejiang University Science B, 12(7), 507-517.

Xue, Z., Wang, C., Zhai, L., Yu, W., Chang, H., Kou, X., \& Zhou, F. (2016). Bioactive compounds and antioxidant activity of mung bean (Vigna radiata L.), soybean (Glycine $\max$ L.) and black bean (Phaseolus vulgaris L.) during the germination process. Czech Journal of Food Sciences, 34(1), 68-78.

Yuan, G., Wang, X., Guo, R., \& Wang, Q. (2010). Effect of salt stress on phenolic compounds, glucosinolates, myrosinase and antioxidant activity in radish sprouts. Food Chemistry, 121(4), 1014-1019.

Zhang, H.M., \& Zhang, Y. (2014). Melatonin: a well-documented antioxidant with conditional prooxidant actions. Journal of Pineal Research, 57, 131-146.

Zhang, N., Sun, Q., Zhang, H., Cao, Y., Weeda, S., Ren, S., \& Guo, Y. D. (2015). Roles of melatonin in abiotic stress resistance in plants. Journal of Experimental Botany, 66(3), 647-656. 